\title{
The Innovation Research of Public Management Model Based on Big Data
}

\author{
Tian Jin \\ Xiangxi Vocational and Technical College, Jishou, Hunan, China, 416007 \\ Hunter2011@Foxmail. Com
}

Keywords: public management, public administration, big data

\begin{abstract}
As a kind of important resources and modern technology, big data provides new paths for local government social management innovation, and creates new opportunities. This paper firstly describes the concept of big data, and then points out the advantages of big data in public management, finally gives the innovations of public management model based on big data in order to provide some references for the related researches.
\end{abstract}

\section{Concept of Big Data}

Big data is a relatively abstract concept. Currently, the definition of the concept of big data is not uniform. Schonberg known as the "the first man who apply big data in business" points out that the "big" in big data does not refer to the absolute number but the processing mode. We will try to collect comprehensive data, complete data and synthetic data, at the same time, the use of mathematical methods to analyze and its modeling, mining behind the relationship, thus predicting the probability of event happening behind. Tu Zipei, a famous information management expert of our country, believes that the "big" in big data an imaginary reference in his book big data. It refers to the human ability to find large value data contained in the big data. Big data is often equated with the concept of "massive data" and "ultra large scale data" terms of formulation. However, its connotation greatly exceeded the traditional data form, also beyond the processing capacity of the existing techniques. Famous research institutions Gartner consulting company Gartner for large data is defined as: big data refers to the need for new treatment mode can have the stronger decision-making ability, insight found strength and process optimization ability of the massive high rates of growth and diversification of information assets. The world famous management consulting company McKinsey's big data is defined as the data which cannot use traditional database software tools in a certain period of time, the contents of the acquisition management and processing of data set.

The most representative definition of many big data definitions is the $3 \mathrm{~V}$ definition. The first $\mathrm{V}$ means volume, namely the data volume is huge; the second V means variety, namely there are a lot of data types in big data, such as text, images, audio, video and so on; The third V means volume velocity, that is the fast processing speed of big data. In addition, International Data Corporation (IDC) believes that big data should also have the high commercial value. IBM believes big data should be veracity. In short, the definition of big data concept can be based on $3 \mathrm{~V}$ or $4 \mathrm{~V}$ or $5 \mathrm{~V}$.

\section{Advantages of Big Data in Public Management}

\section{Broaden Management Channels}

The use of big data technology can greatly promote the government information disclosure to create the basic conditions for public participation in public management. Citizens can express the opinions and suggestions of the government's public administration in the government's portal websites through online comments and comments. The local government can also use social networks, mass media and other media to expand public participation channels. For example, the establishment of community public forum, so that the community residents in the forum to freely and fully express their views, the government through the forum to listen to public opinion and suggestions, so as to improve public management. Public organizations and the people participate in 
public management, in addition to the need to actively guide and encourage the government, but also by the public awareness of participation, participation, etc.. Therefore, under the background of big data, to construct the multi management pattern of public management, the government is trying to expand the channels of citizen participation, and through the media, network, communication and other tools for public opinion to carry out positive attention, from the objective. It also helps to achieve the goal of public governance. Big data technology can help the government to obtain a large amount of data in real time, through the data mining and analysis, which can also capture the public opinion, the demand and innovative suggestions from the public. Decision makers to make scientific and rational decisions by actively concerned about public opinion. In the process of the public management, the government has actually practiced the concept of collaborative management.

\section{Provide Decision References}

Science and technology are the first productive forces. Data is the basis of science. In the era of big data, the decision-making of the government based on big data will be more scientific. Large amounts of data with huge amounts of data and data types characteristics. A large number of structured, semi-structured and unstructured data is produced every day, and the government has a natural advantage in data. First of all, the government has a special data statistics departments and personnel, for example, the National Bureau of statistics will carry out regular census and economic surveys, the financial sector, transportation departments and other departments also have a large amount of data about economic and public operations, and secondly, the government's work on all aspects of the people's livelihood, in the daily administrative activities also naturally accumulated a lot of data. These data are potentially enormous value, through the analysis of the processing, can help the government to make the right decisions and forecasts, to provide scientific basis for government decision-making. In the process of traditional public management, decision makers rely on experience and intuition to make decisions. Experience and intuition are indeed in many times to play an important role in decision-making, but by the limitations of personal limitations, easy to produce errors, resulting in decision-making mistakes. In the era of big data, the government decision makers should strengthen their awareness of big data, in the decision-making process to let the data speak, so that data become an important basis for decision-making and support. Then, the government makes a scientific forecast on the basis of the data collection, mining and analysis.

\section{Improve Supervisory Mechanism}

The core value of big data is predicted. Big data can help decision makers to look ahead to the future to through strengthening the monitoring and early warning mechanism of public management. Moreover, it can improve the scientific decision-making. Big data not only can provide scientific basis for government decision making, but also can obtain and analyze the information feedback mechanism through real time data, discover the problems in decision making, and correct the errors in decision-making. For example, MIT and Harvard University are free to open to the world through online education platform to the world. The purpose is to learn and use the whole world, to facilitate them to collect more data, and through the statistics and analysis of these data to study the behavior of learners in the world. Big data will be placed under the behavior of the public eye. The government's public management activities can be subject to the whole process of supervision.

\section{Innovations of Public Management Model Based on Big Data}

\section{Public Safety}

Government can effectively combat crime applying social media, especially smart mobile devices. Take the Boston Marathon in April 15, 2013 for an example, government quickly identified the suspect through massive social media data and photos in the global. In recent years, big data technology has been widely used in the field of public security and security in many areas of our country. Ji'nan City Public Security Bureau of Shandong province built big data and cloud computing center to grasp the crime trajectory, pre crime hot spots and other aspects play an important role. Ningbo City, the first dangerous chemicals transportation vehicle monitoring platform, greatly improved the level of safety supervision and management of hazardous chemicals. 
We make full use of the convenience of modern technology, with the full use of big data technology, real technology innovation and innovation, and promote the maintenance of public safety technology, intelligent, peace building in a wider field to achieve greater breakthroughs. Using big data to improve the level of public safety, we must dare to crack the problem of public safety management. Under the new situation, new problems are emerging, the social management is more difficult, especially the current social mobility is enhanced, the flow of people, logistics, capital flow, information flow, and each other, forming a huge and complex flow space. The movement not only brings the social vitality, but also increases the risk of public safety. In this case, the people's management and monitoring is clearly not good, and the advantages of big data can be fully played, every time, any form of flow are inevitably in the big data to leave mark. According to these traces we can not only find the clues, but also the data analysis and processing, the formation of early warning, pre-judgment in order to maintain public security to provide effective information data support.

\section{Public Traffic}

Through analysis of hot cities during the spring of mobile phone location signaling and released direct migration index, is a new wave of big data applications. Through the mobile network data filtering, the different travel modes of the division of statistics, the competent department of transportation in charge of dynamic allocation of resources, optimize the transport capacity, better service to the majority of passengers. In addition, through the screening of the mobile network data, it can also carry out the highway network matching, through the modeling analysis to determine the direction of travel, speed and traffic flow, so as to provide real-time traffic and congestion forecasting service. Nowadays, the phenomenon of traffic congestion is not only a difficult problem for the development of major cities, but also has become an outstanding problem that affects the efficiency of urban operation and the life of the residents. Public transport capacity is a serious saturation, transportation infrastructure over load operation, the design and planning of urban road traffic, and so on, is now outstanding issues of urban traffic. And the reasonable use of big data can provide a new way to alleviate traffic problems. For example, we can build a network of large systems, such as the vehicle, the vehicle and the mobile Internet. According to the protocol and data exchange standard, the system can realize intelligent traffic management, intelligent dynamic information service and intelligent vehicle intelligent control, such as the introduction of some enterprises integrating in major cities nationwide parking resources. By the end of the phone platform, government release and the parking information and help owners at any time to master the surrounding parking information, effectively improving the parking space utilization rate and the parking efficiency.

\section{Public Environment}

The scale of the city is gradually expanded, and the living garbage and waste are growing. According to estimates, China's annual production of waste in a million tons, and there is a growing trend. At the same time, the development of urban industry and transportation industry, emissions of a large number of dust and smoke and harmful gas. From the National Health Planning Commission statistics show that at present the incidence of lung cancer in our country is growing at a rate of $26.9 \%$ per year. The cause of death of the third residents in China also showed that lung cancer mortality increased by $465 \%$ in the past 30 years. In recent years, many researches show that accompanied by implementation of the tobacco control measures, smoking causes lung cancer incidence rate rising momentum is controlled obviously, but with environmental impact was positive correlation of lung cancer rate is flying speed rising momentum. Therefore, environmental governance is imminent. We should establish preventive mechanism, timely discovery and efficient processing, which require the support of information technology, through big data related data to carry out the source analysis, on-site monitoring, process control and the establishment of early warning system. At the same time, the full use of digital and information technology, the impact of various factors on the urban environment of data information to be integrated analysis, so that the complex system of urban ecological environment, network, and virtual simulation, can provide scientific basis for the decision of government environmental governance. In 2006, the domestic 
scholars founded public and Environmental Research Center, presided over the development of the "China water pollution map" and " solid waste pollution map " to establish the first public water pollution and air pollution database. The environmental pollution situation will be shown in in an intuitive and simple way based on big data.

\section{Conclusion}

Public management innovation is the realistic need of social development in our country at present. Big data can provide an effective way to achieve the government's public management innovation. With the rapid development of information technology today, strengthening and innovating public management will hardly do without big data, which can provide effective way to realize the modernization of public management. The research on the innovations of big data in government public management still needs to deepen in practice.

\section{References}

[1] Kang Hongxiao, Wang Aidong, The Study of Public Crisis Prediction Based on Technology of Big Data, J., Science and Technology Management Research, 6(2015)175-178.

[2] Yu Hao, The Opportunity, Challenges and Solutions of the Management of Government Data in the Age of Big Data, J., Chinese Public Administration, 6(2015)127-130.

[3] Tang Ying, The Innovation of Social Governance in Big Data Era, J., Journal of Shaanxi Academy of Governance, 11(2014)69-72.

[4] Zhao Qiang, Shan Wei, Government Innovation with Big Data: Creating Public Value Based on Data Flow, J., Forum on Science and Technology in China, 12(2014)23-27. 